\title{
Community-based AIDS Prevention and Care in Africa: Results of four action-research interventions in East and Southern Africa
}

Ann Leonard

Population Council

Esther Muia

Population Council

Follow this and additional works at: https://knowledgecommons.popcouncil.org/departments_sbsr-hiv

Part of the Demography, Population, and Ecology Commons, International Public Health Commons, and the Policy Design, Analysis, and Evaluation Commons How does access to this work benefit you? Let us know!

\section{Recommended Citation}

Leonard, Ann and Esther G. Muia 1998. "Community-based AIDS Prevention and Care in Africa: Results of four action-research interventions in East and Southern Africa." New York: Population Council. 


\section{Acknowledgments}

We wish to acknowledge a number of individuals and organizations for the role they have played in developing and implementing the four interventions described in this report. First and foremost, however, we wish to acknowledge the four community-based organizations that agreed to carry out the interventions: KIWAKUKKI in Tanzania; the National AIDS Control Programme in Uganda, and Kwasha Mukwenu, and the INDENI Petroleum Refinery in Zambia. The staff and voluntary members of these organizations exemplify not only the compassion, concern, and sense of responsibility that got them involved in the first place, but an openness to try new ideas and bear the discomfort that always accompanies even the most positive growth and change. We would also like to thank the consultants who helped to provide the technical assistance required to carry out these interventions: Dr. Fred Wabwire-Mangen, Dr. Joseph Konde-Lulu and their staff at the Institute of Public Health, Makerere University, Uganda; Guiding Systems Consultants of Nairobi, Kenya; Dr. Mubiana Macwan'gi of the University of Zambia; and Alan Harworth, Joseph Nyirenda, and the staff of the Counseling Unit of the Zambia Ministry of Health.

The Community-based AIDS in Africa project has been carried out since its inception with the support of the Positive Action Programme of the Glaxo Wellcome pharmaceutical company. Besides their financial support we would like to specifically acknowledge the help and moral support of Susan Perl, Ben Plumley, Jan Sabatt, Anita Kidgell and Nicky Davies of Positive Action and Andrew Bulloch and Ben Were of Glaxo Wellcome Nairobi. We would also like to acknowledge the Swedish International Development Cooperation Agency (SIDA) for its overall support of the Council's Reproductive Health work in East and Southern Africa, of which this project is a part, and the Council's Robert H. Ebert Program on Critical Issues in Reproductive Health for providing additional support to carry out the counseling intervention in Zambia.

We would also like to thank diane rubino and Christina Tse for their help in the preparation of this report.

Ann Leonard

Population Council

New York
Esther Muia

Population Council

Nairobi 


\section{Introduction}

Despite some medical breakthroughs in the past few years, the number of HIV infected people in the world continues to escalate while the cost of treatment remains beyond the reach of most of those affected. The countries of East and Southern Africa were among the first to experience the full impact of the AIDS epidemic. The response of local people to this overwhelming challenge has been the subject of the Community-based AIDS Prevention and Care in Africa: Building on Local Initiatives project since its inception and remains its inspiration. Initially the AIDS epidemic in sub-Saharan Africa was viewed as a health problem; with time it has come to be seen as a people's problem. In facing AIDS head on, the African people have realized what they are capable of doing for themselves.

Early in the epidemic, when most governments shied away from even acknowledging the presence of the disease, people who died from AIDS complications were said to "have died after a long illness strongly borne" Churches castigated those who had the illness, while communities, and often families, shunned those known to be HIV positive. In the early 1980s, there were even occasions when relatives abandoned their sick and dying at the hospital gates.

Today in Africa, as is evident from the interventions described in this report, governments, church organizations, informal groups, and families are going to great lengths not only to support those who are dying, but to help those who are infected, or affected, and those who are at risk of contracting AIDS. At the workplace, where infected workers were once summarily dismissed, today they are being made to feel that they have something special to contribute in helping their co-workers and their families prevent the spread of infection and care more effectively for those already affected. Today in Africa AIDS is recognized as more than a health problem; it is a social problem, an economic problem--a people's problem. And people are recognized as being an integral part of the solution.

The Community-based AIDS Prevention and Care project's experience over the last year and one-half, in carrying out the four interventions described in this report, goes beyond validating what people are doing at the local level. It provides evidence of how much more effectively these grassroots organizations can be in carrying out their work if provided with some simple but appropriate forms of technical assistance. Modest investments of time, expertise and financial support, executed in a truly participatory fashion, can yield generous returns. It is our hope that others working in this field can benefit by sharing their experience.

\section{A Short Summary of the Community-based AIDS Prevention and Care in Africa Project}

The Community-based AIDS Prevention and Care in Africa: Building on Local Initiatives project is being carried out by the Population Council with support from GlaxoWellcome's Positive Action Programme. Begun in 1993, the project merged the interests of the two organizations--a commercial company and a research organization, both working closely with local nongovernmental organizations--to focus on the then largely neglected area of integrating HIV/AIDS prevention and care activities at the community level. 
The project therefore has sought to:

- $\quad$ explore the range of efforts by organizations in Africa dealing directly with the consequences of AIDS;

- $\quad$ understand the essential components of effective community-based efforts; and

- determine how best to build upon these local initiatives.

\section{Phase I: Identification and Documentation}

To date, the project has focused on five countries in East and Southern Africa: Kenya, Tanzania, Uganda, Zambia, and Zimbabwe. It began with a survey of 65 communitybased organizations in these countries in order to learn more about the type of services being provided, clients served, composition of staff, sources of support, and the like. Eight diverse projects were then selected for documentation as case studies.

- The Zimbabwe National Traditional Healers Association (ZINATHA), Harare, Zimbabwe

- The HIV/AIDS Committee of the INDENI Petroleum Refinery, Ndola, Zambia

- Kwasha Mukwenu, a Children in Distress (CINDI) Programme in Lusaka, Zambia

- The Community Counseling Aides Project of the National AIDS Control Programme in Uganda

- The Kilimanjaro Women's Group in the Fight Against AIDS in Tanzania (KIWAKKUKI) in Moshi

- People in the Fight Against AIDS in Tanzania (WAMATA), in Dar es Salaam

- The Kenya AIDS Society (KAS), Nairobi, Kenya

- The Voluntary Women's Rehabilitation Institute (VOWRI), Nairobi, Kenya

While some of the organizations work primarily with specific groups of people--for example, industrial workers, children, traditional healers, prostitutes)--all of the projects ultimately contribute to the well-being of entire communities.

\section{Phase II: Dissemination}

The case studies report, published in June 1994, provided a unique understanding of both the common advantages of these local initiatives and the common constraints that they face. The report has been widely disseminated both internationally and regionally and, in 1995, a series of workshops were held in the participating countries to disseminate the findings nationally and to draw additional input from other local organizations as to the type of interventions that would be most useful in helping projects such as these to increase their viability and better meet the needs of their clients.

\section{Phase III: Project Interventions}

From a review of the case study findings and the recommendations from the national workshops, four broad problem areas were identified and possible solutions delineated. In Phase III, the project set out to test the following field interventions: 
1. Efforts at education and counseling to date have had only a moderate impact on behavior change. An intervention with the HIV/AIDS Committee of the INDENI Petroleum Refinery, in Ndola, Zambia, endeavored to develop and test new, culturally appropriate methods to increase the ability of community-based organizations to more effectively address the dual issues of prevention and care within both the workplace and the community.

2. As the AIDS epidemic continues to expand, the demand for services from local organizations increases proportionally. Few of these initiatives are well prepared for rapid expansion and/or the changes in leadership and management style that are inevitable over time. The intervention with KIWAKKUKI, in Moshi, Tanzania, was designed to test the effectiveness of a horizontal, participatory approach for strengthening the management capacity of a local, grassroots organization.

3. If local initiatives are to be sustained and empowered to meet the growing demand for their services, they will need to assume greater responsibility for the on-going monitoring and evaluation of their programs. In Uganda, the National AIDS Control Programme (NACP), working with the Institute of Public Health at Makerere University, carried out an intervention that developed and tested a set of simple monitoring and evaluation tools appropriate for use by Community Counseling Aides working at the community level.

4. As all the projects studied have identified a concern with how to care for the growing number of AIDS orphans in their communities, an intervention with Kwasha Mukwenu, a Children in Distress (CINDI) project located in Lusaka, Zambia, was developed to determine if the provision of skills training to orphaned, out-of-school adolescents can: a) increase these youngsters' ability to generate income toward the support of what are often children-headed households, b) provide them with a means of self-sufficiency and, c) at least initially, provide some return of resources to the sponsoring organization.

The four organizations carrying out the interventions were selected because their immediate needs corresponded to one of the problem areas defined above. They also represent a variety of types of organizations (local women's groups, an employment based program, and a community-level program of a National AIDS Control Programme). In addition, staff of each project have demonstrated a high degree of motivation and responsibility in terms of improving program performance, as well as a willingness to seek innovative solutions to problems. They were also projects which did not have a strong external funding base or a particularly high degree of international visibility.

\section{Next Steps}

Two of the interventions were completed in 1997; the two in Zambia are in the final stages and await review and evaluation. However, while it is apparent that all four interventions have met most if not all of the goals outlined at the start of this phase of the project, we cannot emphasize strongly enough the need to continue to monitor their performance over a period of time. This is necessary not only to determine the sustainability of such interventions beyond the period of direct technical assistance, but to re-evaluate various components of the interventions so that modifications can be made that continue to improve program performance. 
We further believe that there is now an important opportunity for cross-pollination between the four participating institutions. As was apparent in the earlier phases of this project, problems faced by local organizations are very similar. We believe that each of the groups involved in the interventions now has something of value to share with its colleague organizations. But it should not stop there. An important next step should be to test the efficacy of carrying out these inputs with other organizations, possibly in different settings, to determine the feasibility of upscaling the interventions.

Regretfully it is too often the case that good experiences are undertaken only to remain virtually unknown to others working in this field. The result is that too often projects end up starting from scratch when there is already a base of experience on which they could build. The countries of East and Southern Africa have been at the forefront of the AIDS epidemic. Where they are now, other countries are soon to follow. This report is one step in sharing what has been learned with our colleagues around the world.

$* * * *$ 


\title{
The Impact of a Simple, Low-Cost System for Monitoring and Evaluating Program Performance at the Community Level
}

\author{
The Community Counseling Aides Project of the \\ National AIDS Control Programme of Uganda
}

The Community Counseling Aides (CCA) project operating with support from the National AIDS Control Programme (NACP) in Uganda, is an example of a government initiative being carried out in collaboration with local communities. As the Ministry of Health seeks to develop local capacity to support and operate these efforts at the community level, they have identified the need to improve the skills of local project staff so that they may begin to assume the responsibility for monitoring and evaluating their own program performance. This is part of an overall strategy on the part of the Ugandan Government to decentralize control and allocation of resources within the health sector to the local level.

\section{Background}

In 1991, the NACP carried out an evaluation of its IEC efforts. The evaluation made clear that while the level of awareness about HIV/AIDS was high, this was not leading to significant change in behavior. The evaluation also revealed a high degree of misconceptions about the transmission of HIV that was impeding attempts to prevent the spread of infection and inhibiting efforts to care for people affected by the disease.

Therefore, among the new approaches implemented by the NACP was community-based counseling. This approach focuses on encouraging local communities to take the initiative in carrying out AIDS education and providing basic nursing care through the deployment of a cadre of trained, voluntary Community Counseling Aides. Most CCAs are peasant farmers, shopkeepers, or petty traders. They are selected by their communities to serve in this capacity because they have demonstrated a sense of concern and responsibility for the well-being of others in the community; they also must be literate at least in the local language. The CCAs are volunteers and receive no monetary compensation for their work. (For more information about the work of the CCA program, see the 1994 publication Case Studies from Five African Countries, available from the Population Council or Glaxo Wellcome's Positive Action Programme).

It is the NACP's goal that the CCA program not only operate but also be administered and supported at the community level. One of the difficulties they were facing in moving toward this decentralized approach was the lack of simple yet effective tools for monitoring and evaluating the work of the CCAs and the performance of the program overall. This need for tools that can easily be used within the community context was also one of the main themes that emerged during the series of national dissemination workshops carried out by the Community-based AIDS in Africa Project in 1995.

\section{The Intervention}


In 1996, the NACP was approached about the possibility of participating in an actionresearch intervention aimed at developing and testing a set of simple tools to monitor and evaluate implementation of the CCA program. With the assistance of the Associate for Reproductive Health in the Population Council's Nairobi office, the Institute of Public Health at Makerere University, Kampala, was identified as a collaborator in this activity. NACP and Institute staff, working with the Population Council, then set out to test the following hypothesis:

\section{With a monitoring and evaluation system and defined indicators of success in place, the output of project activities in AIDS prevention and care at the community level are significantly improved.}

Specifically, the objectives of the study were to:

- Identify indicators of success for CCA activities;

- Develop tools for use as guidelines by CCAs and their supervisors;

- Assess the baseline performance of CCAs;

- Train CCAs in the intervention arm to use the new tools;

- Supervise and guide the CCAs and their supervisors in use of the tools;

- Perform a final evaluation of the performance of the CCAs in order to determine the impact of the tools.

The study was an intervention community trial which lasted 11 months, from January to November 1997.

Selection of Study Sites. A baseline rapid appraisal of six subcounties (three in each of the selected districts) was carried out in order to assess the level of activity of the CCA programs in each district. The purpose of the appraisal was to select four subcounties (two from each district) which were comparable in terms of the level of CCA activity. By March 1997, the four subcounties had been selected--two from Jinja District in the East and two from Luwero in central Uganda. Between 10 and 20 CCAs were active in each subcounty, and one group was selected to participate in the intervention while the other served as the control group. District officials, including the District Medical Officer (DMO) and other administrators involved in health-related activities in both districts, were sensitized as to the objectives of the study.

Baseline Assessment. Baseline surveys were conducted in all four subcounties in order to provide a benchmark against which the impact of the introduction of the tools could be measured. The surveys were completed in May 1997. They included interviews with CCAs, examination of any reports of program activities available, and interviews with members of local households. Qualitative assessments were made on the basis of observation and completion of questionnaires. Members of the public were asked to grade the performance of the CCAs, their usefulness to the community, and their role as a source of information about HIV/AIDS.

During the baseline survey, it became apparent that routine recording of the CCAs' activities was poor and that, for the most part, when it took place most reporting to supervisors was verbal. Few CCAs had been encouraged to make written reports or 
given any guidance in how to go about it. The survey also revealed that the community was not well informed about the work of the CCAs and did not consider that they were effectively carrying out their health education function. Some respondents did not even know who was a CCA, while others thought that CCAs' only job was to treat AIDS patients at the health centers-in fact most of the CCAs' activities appeared to more clinic based than community based.

Developing the Materials and Procedures. At the same time the baseline survey was taking place, a combined team from the Institute of Public Health (IPH) and the NACP were working on development of the tools. They began by drawing up a set of indicators of success for CCA activities that included:

1. CCAs being able to keep a record of all counseling and health education activities;

2. CCAs making regular (monthly) reports to supervisors accurately reflecting the level of their activities;

3. The CCA program becoming well known and better appreciated within the communities where the CCAs are active; and

4. Improved utilization of the CCAs within the community to be measured by rising numbers of clients seeking counseling and health education services, greater demand for health education materials and condoms, and a greater willingness on the part of the community to support the CCA program (this is vital as the CCAs are volunteers and receive no remuneration for their work).

Three specific tools (which are reproduced at the end of the this section of the PDF report) were then developed:

- A report format for the CCAs to use;

- A monthly summary format for the CCAs to complete and give to their supervisors; and

- A supervisor's checklist.

The guiding principle behind development of the tools was that they had to be simple enough to be used and understood by the CCAs but with sufficient scientific content to allow for evaluation on a longitudinal basis. The operational usefulness of the tools was tested in a subcounty which was not included in the study. This activity had not been included in the original proposal but was added in order to insure the quality of the data. The CCAs in the pretest subcounty were trained and used the tools for a full month. Two supervisory visits were carried out and it was apparent that the tools were generally well understood and easy to use; however, a few modifications were made as a result of the pretest. The questionnaires for the baseline and final surveys were also pretested in this district and some modification made.

Field Testing. In May 1997, one group of CCAs in each district was trained in how to use the materials and asked to use the record keeping system for several months (June-October, 1997). At the same time, the control group was asked to continue carrying out their activities as usual, without the assistance of the monitoring tools. 
The CCAs use simple school exercise notebooks that are available at shops throughout the country for about 15 U.S. cents. During the training period, they were shown how to make eleven columns in their notebook where they record: date, village, name of client or group, marital status, age/sex, problem, assistance given, decision of client based on information given, date for follow-up, assistance being provided by the community to the individual or group, and comments. Entries are made for home visits, individual counseling and group education sessions. In some cases the entries made in English but usually they are in locally language.

The method of training was participatory and the CCAs were encouraged to suggest changes to the existing format that were then implemented with the assistance of the researchers. The purpose of using this technique was to develop a feeling of ownership of the tools on the part of the CCAs.

The format of the monthly summary was introduced in the same way, although the immediate supervisors of the CCAs also participated in this activity. Throughout the intervention period, support supervision was provided to ensure that both the CCAs and their supervisors were using the tools continuously and correctly. During the four-month period, research teams visited both sites at least twice each month.

Experience Using the Tools. CCAs report that the monitoring instruments are very helpful to them in their work. As one put it: "Providing a permanent record has really had a positive impact. When making future appointments, this book reminds me because if I only put it in my memory, I may forget."

Each month the CCAs fill in a simple monthly summary which they turn in to their supervisor. Maintaining the notebooks has helped them with this task. As one CCA notes: "They have helped me when I am doing my monthly report summary. When the supervisor comes along it makes it easier for him." Another notes that the report she writes each month is now brief because the information is all in her book. Another states that "before I would forget what I did earlier in the month, but now I have the information in the book." One CCA, however, noted: "one negative is that it forces us to work a lot because if there isn't much in your record book, it becomes obvious that you are not doing enough so you have to work harder."

The supervisor then prepares an overall summary which is given to the District Medical Officer and to the local sponsoring organization. As one supervisor put it: "I am happy about the program, especially as introduction of the books has given them (the CCAs) an identity." In addition, he says: "it helps me to supervise because when I visit the CCAs I see their book which tells me what they are doing."

Evaluation. In October 1997, researchers from the Institute of Public Health returned to the field to begin assessing the impact of the interventions. They interviewed the CCAs, their supervisors, and sponsors in both the participating and control groups in order to determine the impact of use of the tools on the performance of the CCAs and the supervision they receive from those in charge of the program. They also carried out a second community survey with the same questionnaires used for the baseline to determine if there was any change in terms of the community's awareness of or level of support received from the CCAs as a result of the intervention.

\section{Outcomes}


Throughout the period of the intervention, the researchers found that the CCAs greatly valued the monitoring tools. They enjoyed the practice of keeping a permanent record of all their activities in a standardized format that was also easy to use. Barbara from Busede says that "when I visit my client I make some notes and then I take them home and write in my book." That way "it is easier to know what you have done and what you want to do with the books." In Busede, the local medical assistant also reviews the reports.

"They help me to know how much they are working. They then bring me patients and the information is useful in assisting them."

The final evaluation survey showed a big difference between the intervention and control arms of the study. While the CCA program is becoming better known and understood in both areas, the process is happening much more rapidly in the communities where the new monitoring and evaluation tools have been put to use. While the CCAs in the intervention arm could proudly display their notebooks showing all of their activities neatly recorded, those in the control arm had nothing tangible to show for their work.

The final household survey also demonstrated that in the communities where the CCAs had begun using the monitoring and evaluation tools, people were now more aware of their activities and rated their performance more positively than in the control arms. For example, during the baseline survey, only 23 percent of household heads could describe who the CCAs were. In the final survey, the number had risen to 79 percent in the study arm. Likewise, the proportion who found the CCAs' work useful at baseline was only 16 percent. At the end of the project, this number had increased to 61 percent.

The researchers also found that the NGOs supervising the CCAs, as well as staff at the local health centers were impressed by the improvement in the quality of the reports generated through this intervention. They in turn have recommended that use of the tools be extended to other areas.

PLAN International is the local NGO supporting the CCA program in Luwero. The summaries have been very useful in planning their activities and evaluating how best to assist the CCAs. "Before they were just handing in reports," notes Lily Joyce Potter, the Health Coordinator. "Now there is a change. Now it is systematic. They bring the reports regularly. Now if they can tell you some problems or what we should be doing to make their work easier, it helps you to plan more effectively."

In Luwero, supervisors actually forwarded copies of their monthly report to the DMO's office. The reports have made such an impression that, for the first time, the CCAs are to be included as one of the subcounty's recognized health programs. As such, they will be represented when decisions on how to allocate subcounty funds are made, meaning that the CCAs will also receive direct support from the local government for the first time.

Researchers from the IPH observed significant improvements in performance, job satisfaction, and public satisfaction with the work of CCAs using the monitoring and evaluation tools. They thus have concluded that the use of these simple tools and procedures holds the potential to significantly improve the performance of community volunteers as well as to help raise their self-esteem and improve the public perception of the program.

\section{Problems Encountered}


Problems encountered in carrying out the intervention did not directly involve the tools. Rather, the process of introducing the intervention revealed some problems within the program that need to be addressed.

First, because the NACP has seen the CCA project as becoming a locally operated and maintained initiative, there are variations in how the program is carried out in different subcounties. For example, in Luwero, the supporting NGO is located nearby and maintains close ties with the local health center. The direct supervisor for the CCAs is a staff member at the center and is there to give them ongoing support. Thus there was no difficulty in carrying out the training of the CCAs in the use of the new materials or in supervising their performance during the intervention period.

In Jinja, however, the supporting NGO is located in the district headquarters while the intervention took place in a rural subcounty a good hour's drive away. Despite the fact that the supervisors are part of a mobile health care project, they were not available to provide ongoing support to the CCAs most of the time. Rather, the Aides had informally begun to seek the support of the medical assistant assigned to the local health center. Therefore, the NACP has realized the need to ensure that CCAs have supervisors who are located in the area where they are working and who are available to provide them with ongoing support.

While the CCAs were delighted with the evaluation tools, they identified a number of constraints that they felt are affecting the quality of their work. For example, they feel that they need more training on medical issues and terminology. "I feel that we need more medical training," says Deborah from Luwero, "because many times people ask us if they should stop taking their medication and we don't know." The CCAs in Busede complained that they lacked informational materials to give clients and requested that the NACP provide them with handouts, preferably in local languages.

In both Luwero and Busede, one of the main frustrations of the CCAs was the fact that they are frequently asked by clients to accompany them to the health center or hospital. Even though medical services are free to people with AIDS and TB in Uganda, in the case of Busede it is necessary to go all the way to Jinja simply for an HIV test. This is a long trip that can take as much as half a day, with no reimbursement available for the cost of transport. Currently it is not possible to do testing at the local health center because of the lack of electricity in the village. In Luwero, while PLAN International's mobile clinic provides medicine and food for those who are bedridden, the CCAs say they sometimes feel forced to provide something to those in immediate need. "If someone is very sick and would like to go to the hospital or needs some drugs, or needs an HIV test and cannot manage on their own," says Mastula, "then I take from my own pocket to take care of people because I am seen as the local health worker." Teopista adds that sometimes "a person may look like they have AIDS and needs to be tested but they don't have the money. Sometimes we are forced to pay for the test " (which cost about U.S. $\$ 2$ ). So while the guidelines of the CCA project specifically indicate that they are not expected to give medicine or other material assistance, the reality of daily life in their communities often puts the CCAs on the spot.

It is for this reason that the official recognition of the CCAs in Luwero is an important breakthrough, as it will allow them to have a voice in the planning of health activities in their area and will make them eligible to receive some support from the local 
government. The CCAs say that they have not thought about what they will do with these resources as they don't know how much money will be involved. However, when the support comes they intend to sit down together and discuss how best to us the money. The group is also thinking about setting up some kind of income-generating activities so, as Geoffrey concludes, "we will have some funds to use to provide assistance when needed."

\section{Next Steps}

Within the past year, the NACP in Uganda has been combined into a larger unit as part of the country's expanded STD/AIDS program funded by the World Bank. Under the new program, funds are being made available at the district level where a decision can be made whether or not to conduct an outreach program of home-based care. The STD/AIDS program will, however, continue to conduct the training of trainers for these programs, while the actual training and supervision of health volunteers will continue to be the responsibility of a local organization named by the district. Based on the successful use of the monitoring and evaluation tools in the two districts participating in this intervention , the STD/AIDS program is now planning to incorporate the methods within their ongoing training program. They are also discussing with the IPH ways of collecting and presenting information gathered by the CCAs to decisionmakers within the STD/AIDS program and the Ministry of Health.

Meetings were held in both Jinja and Luwero to disseminate the results of the evaluation to all those involved in the intervention. The tools will also be shared with other groups working on community-based AIDS initiatives in Uganda. These groups will be invited to participate in a one-day meeting in Kampala to publicly disseminate the findings. The meeting will provide an opportunity to discuss the applicability of the materials for use by other organizations. Meanwhile, the expertise gained by the Institute of Public Health through their participation in the intervention will remain a resource accessible to other community-based health initiatives in Uganda and the East Africa region.

\section{Lessons Learned}

1. Materials as simple as a school exercise book and a few sheets of paper can become the basis of a very effective means of continuously monitoring and evaluating the performance of community workers.

2. With appropriate training and support, community workers with basic literacy skills can effectively understand, make use of, and benefit from the systematic monitoring of their activities.

3. Local organizations providing support and supervision for community workers are better able to carry out this role when provided with timely and succinct information collected through such a monitoring system.

4. The information collected and summarized through such a system can be instrumental in garnering additional support for a community program from local government, health authorities, and the community at large by creating greater awareness of the work they are doing. 
5. While designed for use at the local level, the information provided through such a system can also provide important feedback to a national organization, such as the NACP, in terms of what effect its programs are having in the field. 


\section{CCA Monthly Report Format}

Name:

Subcounty:

Parish:

Village (LC1):

Monthly Report for: month: year:

Total number of clients:

New clients:

Old clients:

Number of clients admitted to hospital:

Number of clients referred for HIV testing:

Number of clients dead:

Number of group talks given:

Number of condoms supplied:

Number of educational materials supplied: 


\section{Supervisor's Monthly Report}

Month:

Subcounty:

Supervising institution:

Name of supervisor:

Total number of CCAs under your supervision:

Number of visits to CCAs this month:

Assistance provided by CCA by supervisor:

Activity

Total number

1. Clients seen

2. New clients

3. Group talks given

4. Clients receiving help from CCA

Information

Condoms

Referred for further care

Educational materials

Referred for HIV testing

5. Clients receiving the following

Food

Medicine

Money

Social visits

Religious visits

1. Constraints identified:

2. Suggestions/recommendations for better supervision:

$$
* * * *
$$




\title{
Testing a Participatory Aproach to Assisting a Fast-Growing Local Organziation to Improve Its Management and Organization Structure
}

\section{KIWAKKUKI, the Kilimanjaro Women's Group in the Fight Against AIDS, Moshi, Tanzania}

\author{
KIWAKKUKI is the Kiswahili acronym for (Kikundicha Wanawake Kiliminjaro \\ Kupambana na Ukinwi) the Kilimanjaro Women's Group in the Fight Against AIDS, a \\ community-based nongovernmental organization operating in the city of Moshi and the \\ surrounding rural area in northern Tanzania. KIWAKUKKI gives almost equal attention \\ to education and care activities in its work.
}

\section{Background}

KIWAKUKKI was founded in December 1990 when a group of women got together informally to organize an AIDS Week in the town of Moshi. Following the success of the week's activities, a number of these women decided they would form a women's organization in the Kilimanjaro region to support vulnerable members of their community in dealing with the AIDS epidemic. Their ad hoc activities have since evolved into a range of services that include information, education, home visiting and care, support for people living with AIDS (PWAs), income-generating activities aimed at supporting the organization, and providing the means to care for those in need. All of these services are provided primarily by the volunteer members of the organization. (For more information about the work of KIWAKUKKI, see the 1994 publication Case Studies from Five African Countries available from the Population Council or Glaxo Wellcome's Positive Action Programme.)

Like many successful, rapidly-growing grassroots organization, KIWAKUKKI's ad hoc structure was no longer proving effective in managing the increasing number of volunteers and program activities the was undertaking. Therefore, improvement of the group's organizational structure and management system were identified as common problems affecting local initiatives in developing countries as an immediate need. Similar difficulties were identified during the series of national dissemination workshops carried out as part of the Community-based AIDS in Africa project during 1995.

\section{Intervention}

In 1996, KIWAKUKKI was approached about the possibility of participating in an actionresearch intervention aimed at assisting the organization to define its structural and management needs and outline the steps necessary to undertake change. The Council's Associate for Reproductive Health in Nairobi identified Guiding Systems Consultants-a private organization based in Kenya but with experience working throughout East Africa-as having the technical expertise needed to help KIWAKUKKI improve its management capability through the application of participatory techniques. Working together, KIWAKUKKI, the Council, and the consultants set out to test the hypothesis that: 


\section{A participatory, horizontal approach to planning and analysis can assist a fast-growing local organization to improve its management and organizational structure to better carry out program activities, to more effectively respond to changes occurring within and outside the group, and to broaden the base for sustaining its work.}

\section{The First Workshop}

In September 1996, a four-day planning workshop involving representatives from the stakeholders of KIWAKUKKI (e.g., members, donors, collaborators, and others) was held in Moshi to assess and document the current situation. The approach applied during the workshop was Objective Oriented Project Planning, otherwise know as the Logical Framework Approach (LFA). The basic idea underlying the approach is that planning is an interactive process that takes place not only before implementation of the intervention but also throughout the duration of the entire activity. The most important features of are: metaplan visualization (where all ideas and suggestions of participants are written out and put up for viewing); permanent visualization (where ideas become a permanent reference to be used in the subsequent planning process); a team approach (whereby all inputs into the planning process are accepted by consensus); and successive planning steps (a process that leads to development of a Logical Framework Matrix [reproduced at the end of this section of the PDF file] where objectives are arranged in a logical way. These included: the activities to be carried out in support of each objective, the risk factors anticipated, indicators of measuring progress and achievement, and the data required for evidencing the indicators.) Working with a moderator from the consulting organization, the participants carried out the following steps:

- Identification of all stakeholders involved in KIWAKUKKI's activities;

- Analysis of constraints affecting the organization;

- Identification of the organization's strategies and alternatives

- Setting the organization's objectives;

- Developing a Logical Framework Matrix for the organization's activities;

- Review of KIWAKUKKI's organizational structure;

A comprehensive list of stakeholders identified through this process included donors and support organizations, consultants, collaborators, religious institutions, beneficiaries of KIWAKUKKI services, the government, and the organization itself. The Analysis of Constraints determined that the group's core problem was inadequate delivery of services. From here, a problem tree was developed which revealed that the immediate causes of the core problem were: inadequate management, insufficient nonhuman resources, and an unrealistically broad scope of work. Working in small groups, each of these problems was then analyzed in detail.

Inadequate Management was seen as primarily a problem of overloading some staff and over-reliance on volunteers. Staff overload in turn was attributed to inadequate transparency within the organization (i.e., everyone knowing what is going on), gender imbalance, not enough delegation of duties and inadequate number of staff. Over-reliance 
on volunteers was seen as the result of not having enough people due to increased workload, poor planning, and lack of funding.

Inadequate Non-Human Resources were generally attributed to lack of funding (from donors or via income-generating activities), lack of fund raising skills, and need for greater support from collaborators.

Unrealistically Broad Scope of Work was seen to be the result of the large geographical area being covered, having too many activities on the ground, lack of focus, and inadequate staff. In particular it was noted that the group was trying to cover too many aspects of prevention and care and that there was inadequate planning due to a lack of clearly defined objectives. This in turn was exacerbated by the lack of full-time staff, inadequate time available from volunteers, low skill level among staff and volunteers, and insufficient motivation on the part of some volunteers.

Once all the factors were delineated, the participants revisited the problem tree and identified the branches where KIWAKUKKI could intervene given the constraints of resources available, probability of success, political feasibility, cost-benefit, social risks, time, institutional capacity, gender concerns, and sustainability. Through this process the group identified potential strategy options. From here, a Logical Framework Matrix was developed that outlined the why (purpose), what (expected achievements), how (activities to be undertaken), which (external factors necessary for success), measurement (objectively verifiable indicators), where (the data can be obtained), and cost.

From the potential strategy areas carved out under the problem tree, the participants ultimately defined four outputs that KIWAKUKKI was to achieve within one year.

- Improve the organization's management capacity;

- Develop an appropriate work plan;

- Obtain the capital necessary to carry out the organization's activities;

- Strengthen the links between KIWAKUKKI and current/potential collaborators.

Under each of these outputs, a list of specific activities was delineated. In particular, it was proposed and endorsed by all present that:

1. An executive project coordinator be hired as a full-time employee and serve as the Secretary to the Steering Committee.

2. A competent administrative secretary be employed full-time to run the office.

3. A health education officer, secunded from the Ministry of Health, operate the health education program out of the organization's headquarters.

4. A steering committee be established composed of: a representative of the PWA group, honorary members capable of fund raising, the treasurer, the chairperson, and those heading each of the group's various activities.

In evaluating the first workshop, the participants had high praise for the participatory methodology. In particular they valued learning how to start planning by looking at a negative situation and then moving towards the positive in terms of 
implementation. They also valued the skill of the facilitators in making the workshop a team-building experience. The main complaints had to do with too much being covered in too short a time. Many participants felt this type of activity is something KIWAKUKKI should do on a regular basis, perhaps involving different participants, but spread over a longer period of time.

Implementation. Following the workshop, the group developed a new organizational chart, breaking their various activities (education, counseling/home visits, income-generating, fund raising, etc.) into teams. The head of each team is elected by team members and serves as a member of KIWAKUKKI's Steering Committee.

The group also decided that in addition to a secretary for the headquarter's office, paid staff should also include a coordinator who would oversee the day-to-day operation of the organization. There would also be officers (Chairperson, Vice-Chairperson, Secretary, and Treasurer) elected by the membership. These officers would form the Executive Committee which would directly oversee the work of the coordinator and could be called upon to make interim decisions without the need to convene the full Steering Committee. To address the problem of geographical spread, ten branches were established to promote decentralization and facilitate the ability of groups to act according to local priorities.

Overall the new organizational structure worked well during the first year. Division of work into committees has helped to reduce overlap and evened out the burden of responsibility among the members. The branch system is also seen as a real success, serving as a vehicle to increase the group's membership and outreach, while the fund raising committee is seen to be broadening KIWAKUKKI's base of support.

Evaluation. After one year, a two-day follow-up evaluation workshop was held in November 1997 to assess the degree to which the goals and objectives had been met, to determine where additional changes would be required, and to define next steps in refining the management and organizational structure of the organization. The same participatory approach used in the first workshop was repeated here and the evaluation process followed a team approach, with the guidance of the facilitator, whereby all decisions were arrived at through consensus.

Participants were divided into two groups and asked to evaluate the four outputs that had been determined the year before in terms of: major achievements thus far, ongoing and incomplete activities, major constraints and remaining problems, lessons learned, and to come up with possible solutions to problems identified.

In evaluating the follow-up workshop itself, participants were asked what had impressed them most during the event. KIWAKUKKI's willingness to evaluate its weaknesses in order to make necessary changes was lauded. Areas noted for improvement included greater involvement of the branches in such workshops or even helping branches organize similar workshops for their own members as well as greater involvement of PWAs in the process.

\section{Outcomes}

Many important achievements were identified during the evaluation workshop. KIWAKUKKI's organizational structure had been revised, the roles of staff members and officers defined and coordinators elected for the education, counseling, and fund-raising 
teams. Branches were established and are functioning well. Monthly membership meetings are held, revolving fund and counseling activities have been established within the branches and a training of trainers workshop has been conducted. A Center of Hope has been established for PWAs to help them engage in income-generating activities and a small shop opened to help support orphans.

Dora is a PWA. She moved to Moshi town after her husband left, taking their four children with him. Shortly after her arrival, she went for an AIDS test and learned she was HIV-positive. It was at the testing center that she learned about KIWAKUKKI and their PWA group. "We meet just to talk and share ideas about income-generating activities, " says Dora. "There are 26 in the group, but three died last year." The PWAs get loans from KIWAKUKKI to develop income-generating activities and their earnings are deposited in a bank account. They are also given money to cover the cost of transport to attend meetings. To date members have used the profits to buy dishes and a new sewing machine. Several members are tailors and this machine, located at headquarters, is used to produce large orders.

Recently Dora was asked by KIWAKUKKI if she would like to run the small shop they have started at headquarters for a salary of TSh. 18,000 per month. "Most people buy snacks to eat while they watch the videos," she reports. To date she has not been trained to talk to visitors about HIV prevention or AIDS, but it is something she would like to do.

In terms of fund raising, a special committee has been formed. The donors they contacted have contributed a total of TSh. 9,731,631 (US \$16,219) during the past year. Other special fund raising activities included a dinner dance, a luncheon, and the sale of KIWAKKUKI items through a local coffee shop. A revolving fund committee has also been formed and the group has opened a bank account with the Cooperative and Rural Development Bank. KIWAKUKKI has also started putting out a donation box at their monthly meetings so that members can contribute any amount-even loose change - to support the PWA activities. For some time they did not even bother to open the box, but when they finally did they realized they had collected TSh 5000 (apx. U.S. \$8). This was then divided among the members of the PWA group so that each received TSh. 600 . Based on the success of this effort, KIWAKUKKI has now received permission from a number of local merchants to periodically place the box in their establishments to raise money from their customers.

Grinding mill activities have been started with four branches to help raise money to support their work. In terms of increasing collaboration with other organizations, a list of all potential collaborators was prepared and five meetings held with them. KIWAKUKKI collaborated with several local women's groups to hold demonstrations protesting the growing number of rapes in Moshi town and they held a community awareness raising session to inform people about the negative effects of female genital mutilation.

Among the management problems identified was the overlap between the duties of the chairperson and the coordinator, especially in terms of representation of the 
organization in external affairs, the need for sub-committees to report directly to the coordinator, and the need to keep members better informed of what is happening within the organization-especially if they cannot regularly attend meetings. Greater representation of the branches on committees was also set as a goal. In terms of planning, it was felt that too many issues are brought up at committee meetings causing difficulty in prioritizing what is most important. The Center of Hope's activities have not been as successful as expected while the orphans program has been developed without direct input from the committee supposed to be overseeing its development. The result is that the community's expectations of KIWAKUKKI's ability to help orphans are now beyond what can be sustained. At the same time, the number of orphans continues to increase faster than was anticipated.

In the fund raising area, a number of missed opportunities were noted often due to lack of proper coordination. Over the past year, the drought in the area was another reason why KIWAKUKKI has been less successful in generating local contributions. At the same time, it was felt that there was a need to make the general population more aware of KIWAKUKKI's activities. Regarding increased collaboration with other local organizations, the competition for limited resources was noted as a reason why some local groups are reluctant to work together more closely.

\section{Problems Encountered}

As was expected, there were a few areas where change was less than was envisioned when the new organizational structure was decided upon at the workshop. In particular there was considerable controversy surrounding the selection and supervision of the person holding the paid position of coordinator. As is the case with many organizations, the focal point of the organization's activities in recent years has been one of its most active founding members. While KIWAKUKKI members greatly love and respect their former Chairperson, when she assumed the newly created role of coordinator there was a good deal of grumbling behind the scenes that held the potential to be highly disruptive to the organization.

There was also concern among many members that too much attention was being given to the organization's income-generating activities. They felt that KIWAKUKKI was founded as a voluntary group to support families affected by AIDS and to offer AIDS education to the community. There was concern that the focus of attention among the women's groups who have received support in the form of oil pressing or maize grinding machines is being diverted from the original intent of KIWAKUKKI.

While there was much discussion among members about these issues, no one wanted to confront their esteemed colleague about their concerns. However, the fact that a second workshop was to be held at the end of intervention year meant that a safe and open venue was provided where these issues could be openly discussed and resolved.

\section{Next Steps}

As a result of the last workshop a number of important changes have already taken place. The responsibilities of the Chairperson and Coordinator have been clearly defined. A job description for the coordinators was drawn up and advertised; a new coordinator hired from outside the organization began working in early 1998 . The special contribution of 
the former chairperson and founder has been acknowledged and she will continue to contribute her special skills to the organization, especially in terms of fund raising.

While the internal problems that KIWAKUKKI is currently facing are difficult ones, they are common to most growing organizations. Still the voluntary membership continues to be strongly supportive of the group and their reputation in the community and within Tanzania is strong. Another one of the founding members and a former chairperson of the group, who had raised a number of concerns about the direction of the organization during the year of the intervention perhaps best summed up the spirit of KIWAKUKKI when she said, "In the end, all we really need to do is love one another and everything will be all right."

The participatory nature of the workshops provided an opportunity for individual group members to voice their concerns and problems with the result that positive steps could be taken towards developing a more open and decentralized organization. The former chairperson herself thinks that tremendous change has taken place, "Making things more open and with more coordination." In fact the whole experience as an eye-opener for her, "I was surprised to learn that people were so aware of everything that was going on." She felt the process was also very helpful in identifying potential collaborators that KIWAKUKKI could have been working with earlier.

Having a follow-up workshop was an essential part of the process of change because it provided another structured format where everyone could openly discuss the changes - and frustrations - that had taken place during the year and evaluate what worked, what didn't work, what changed, and how to proceed in the year ahead.

\section{Lessons Learned}

1. Use of a participatory process can be successful in assisting a community-based organization identify important management and organizational problems and develop a series of practical solutions.

2. The importance of identifying facilitators who are well versed in the participatory process, knowledgeable about the culture, and familiar with the work of nongovernmental organizations in the particular setting cannot be overemphasized.

3. The participatory approach offers significant advantages in terms of providing a safe, open and facilitated venue in which a wide variety of individuals with different perspectives can feel comfortable expressing their concerns. The process encourages the development of a spirit of team work and can help diffuse potential divisiveness within an organization.

4. The major difficulty encountered in the use of such a process is related to the process of change itself which is, at best, a process of trial and error. In attempting to make things work better, some situations may appear to get worse-or at least become more noticeable. For this reason, there is a need to provide some sort of ongoing technical assistance to assist a group in assessing what is going on during the process and, most importantly, to offer another forum (such as 
the follow-up workshop) where new concerns raised during the implementation phase can be discussed and resolved.

5. The current intervention has made clear that it is possible for a community-based organization, through the use of a participatory process, to identify indicators for determining the success of the intervention. For example, KIWAKUKKI developed a set of indicators for each of the four outputs they set out to achieve during the year. These included a list of activities to be carried out (hiring a coordinator, revising the organizational chart, etc.), review of meeting reports (to determine participation and actions take), recordkeeping (of members, clients served, training activities, income generated, funding received) etc.

6. Ultimately the people who make up grassroots organizations who are their own greatest resource. The intervention undertaken with KIWAKUKKI has clearly demonstrated that, with appropriate guidance, members and staff are quite capable of critically assessing the performance of their organization and taking the steps necessary to bring about the required change. 


\section{Logical Framework Matrix (LFM)}

\begin{tabular}{|c|c|c|c|}
\hline $\begin{array}{c}\text { Summary of } \\
\text { Objectives/Activities }\end{array}$ & $\begin{array}{c}\text { Objectively Verifiable } \\
\text { Indicators }\end{array}$ & Means of Verification & Important Assumptions \\
\hline $\begin{array}{l}\text { Overall Goal (OG) } \\
\text { The spread of HIV/AIDS } \\
\text { in the country considerably } \\
\text { reduced and controlled }\end{array}$ & $\begin{array}{l}\text { The number of reported } \\
\text { HIV/AIDS cases is } \\
\text { reduced by } 3 \text { percent by } \\
\text { the year } 2007 \text { in Tanzania }\end{array}$ & NACP reports & $\begin{array}{ll}\text { Assumptions of }(\mathrm{OG}) \\
\text { - } \quad \text { constainability } \\
\text { governmed } \\
\text { - } \\
\text { Pattern of spread } \\
\text { remains the same }\end{array}$ \\
\hline $\begin{array}{l}\quad \text { Purpose }(\mathrm{P}) \\
\text { Sustainable information, } \\
\text { education, and care for } \\
\text { preventing and reducing } \\
\text { spread of HIV/AIDS in } \\
\text { Kiliminjaro region } \\
\text { provided }\end{array}$ & $\begin{array}{l}\text { The level of } \\
\text { HIV/AIDS awareness } \\
\text { among Kiliminjaro } \\
\text { population is } \\
\text { increased by further } \\
10 \text { percent } \\
\text { The number of } \\
\text { reported HIV/AIDS } \\
\text { cases is reduced by } 20 \\
\text { percent by the year } \\
\text { 2001 in Kiliminjaro }\end{array}$ & $\begin{array}{ll}\text { - } & \text { Regional AIDS } \\
\text { control coordinator } \\
\text { records } \\
\text { - } \\
\text { District AIDS control } \\
\text { coordinator records } \\
\text { - } \\
\text { Specific hospital } \\
\text { records }\end{array}$ & $\begin{array}{l}\text { Assumptions for attaining } \\
\text { - } \quad \frac{(\mathrm{P})}{\text { There will be }} \\
\text { willingness and } \\
\text { commitment from } \\
\text { community } \\
\text { Community will } \\
\text { continue to accept } \\
\text { KIWAKKUKI } \\
\text { services } \\
\text { There will be support } \\
\text { from government and } \\
\text { policymakers }\end{array}$ \\
\hline $\begin{array}{l}\frac{\text { Results/Outputs }}{\text { Management capacity for }} \\
\text { KIWAKKUKI improved }\end{array}$ & $\begin{array}{l}\text { By the end of } 1997 \text {, } \\
\text { KIKWAKKUKI staff } \\
\text { capability to work } \\
\text { efficiently and effectively } \\
\text { will be increased }\end{array}$ & $\begin{array}{l}\text { Organizational chart, } \\
\text { training records, job } \\
\text { descriptions, minutes of } \\
\text { meetings, constitution, } \\
\text { annual/financial reports }\end{array}$ & \begin{tabular}{ll}
\multicolumn{2}{l}{ Assumptions for Achieving } \\
- $\quad$ Outputs \\
- $\quad$ Manailability of funds \\
- $\quad$ Thement \\
$\quad$ of meme is commiters \\
\end{tabular} \\
\hline $\begin{array}{l}\text { Appropriate plan for } \\
\text { KIWAKKUKI developed }\end{array}$ & $\begin{array}{l}\text { By December } 1997 \text { a plan } \\
\text { of action will be in place } \\
\text { and at least eight branches } \\
\text { decentralized and } \\
\text { effectively functional }\end{array}$ & $\begin{array}{l}\text { Minutes of meetings, } \\
\text { training records, training } \\
\text { package, events calendar, } \\
\text { job description of peer } \\
\text { education, branch reports, } \\
\text { minutes of branch } \\
\text { meetings, financial reports } \\
\text { from branches, evaluation } \\
\text { reports. }\end{array}$ & \\
\hline $\begin{array}{l}\text { Capital to carry out } \\
\text { activities acquired }\end{array}$ & $\begin{array}{l}\text { By December } 1997 \text {, a } \\
\text { fundraising team is } \\
\text { functional and at least } \\
\text { three fundraising strategies } \\
\text { in place }\end{array}$ & $\begin{array}{l}\text { Project proposal, financial } \\
\text { records, income-generating } \\
\text { activities, write-ups, } \\
\text { minutes, fundraising team } \\
\text { evaluation }\end{array}$ & \\
\hline $\begin{array}{l}\text { Links between } \\
\text { current/potential } \\
\text { collaborators and } \\
\text { KIWAKKUKI } \\
\text { strengthened }\end{array}$ & $\begin{array}{l}\text { By December } 1997 \text { at least } \\
50 \text { percent of identified } \\
\text { collaborators will have } \\
\text { functional links with } \\
\text { KIWAKKUKI }\end{array}$ & $\begin{array}{l}\text { Minutes of meetings with } \\
\text { collaborators, reports from } \\
\text { collaborators }\end{array}$ & \\
\hline
\end{tabular}


*****

\title{
Using Cultually Appropriate Education and Counseling Methods and Mterials for HIV/AIDS Prevention and Care: Feasibility of Development and Potential for Improved Effectiveness
}

\author{
The HIV/AIDS Committee of the \\ INDENI Petroleum Refinery in Ndola, Zambia
}

The INDENI Petroleum Refinery is located in the Copperbelt Province of Zambia. It is one of the 65 companies that participated in a Ministry of Labour and Social Security (MLSS) effort to promote AIDS education and prevention in the workplace. While the HIV/AIDS Committee at INDENI initially focused on it's predominantly male work force, they soon began an outreach program for the families of INDENI staff in the company's housing complexes.

\section{Background}

INDENI's HIV/AIDS activities date back to 1987 when concern about the increasing number of deaths among workers motivated the Managing Director to alert the company's board of directors about the medical problems they were facing. It was at just about the same time that the Ministry of Labour and Social Services began its workplace project on HIV/AIDS prevention and care, and INDENI was one of the companies that agreed to participate. An HIV/AIDS Committee, which represented the company's various departments, was formed under the direction of INDENI's resident nurse. The committee carries out a variety of activities aimed at increasing awareness of AIDS among its employees as well as providing them with condoms and medical care. Those willing to take an HIV test are referred to the local hospital at the company's expense.

Besides carrying out programs addressed at workers and the training of committee members as peer counselors (with support from the Morehouse HIV/AIDS project) the committee also addresses the needs of the employees' families, most of whom reside in company leased houses in specific compounds. Initial attempts to reach family members through talks in the community did not prove fruitful, so the committee came upon the more successful approach of supporting the formation of women's groups within each compound. These groups meet regularly and carry out some income-generating activities aimed at helping themselves and those within the community who have been directly affected by the AIDS epidemic. (For more information about the development and operation of the INDENI program, see the 1994 publication Case Studies from Five African Countries available from the Population Council or GlaxoWellcome's Positive Action Programme.)

Yet despite all of these activities, staff of the HIV/AIDS Committee remained frustrated by their lack of effective counseling skills that would enable them to really begin to make a difference in terms of people's attitudes and behavior. This is not surprising given that IEC campaigns to date, while proving quite successful in conveying information about the epidemic--how you get it, how to prevent it-have been much less effective at motivating changes in behavior. Most counseling approaches have adopted a Western 
notion of individual autonomy that assumes that an informed person can and will act in her/his own best interests based on that information, regardless of the cultural and social milieu within which she/he lives. This lack of truly effective interventions able to affect behavior modification was a recurring theme during the series of national dissemination workshops carried out by the Community-based AIDS in Africa project in 1995 as well as throughout the literature on HIV/AIDS prevention.

\section{Intervention}

In 1996, INDENI was approached about the possibility of participating in an actionresearch intervention aimed at assisting them to develop and test a more culturally appropriate approach to counseling. Working with contacts in Zambia and the Southern Africa region, the Population Council Associate for Reproductive Health based in Nairobi identified the most appropriate source of technical expertise to work with the INDENI HIV/AIDS Committee and their team of peer educators. This is the Counseling Unit of the Ministry of Health (MOH), headed by Professor Harworth of the University of Zambia. This group has pioneered development of a more appropriate approach to counseling within the Zambia context. Working together, INDENI, the Population Council and the Counseling Unit set out to test the hypothesis that:

\section{Locally developed, culturally appropriate education and counseling methods and materials will improve the acceptability and enhance the adoption of appropriate prevention and care behavior at the community level.}

Developing a Training Program. Representatives of the three participating organizations first met together to develop the overall plan for the intervention which would be divided into two phases between July 1997 and March 1998.

Phase I

- First training workshop for facilitators (5 days)

- Field work for facilitators (approx. 4 weeks)

- Follow-up training for facilitators (5 days)

- Additional field work (approx. 8 weeks)

Phase II

- Development of curriculum for training community-based peer educators

- Training of peer educators (5 days)

- Period of fieldwork for peer educators work within the communities (6 weeks)

- Follow-up workshop (5 days)

- Evaluation of the project

The First Workshop. Nine men and one woman participated in the first training workshop for facilitators which was held at an off-site facility for five days in August, 1997. (A summary of activities for this workshop is included at the end of this section of the PDF file.) As the employment ratio at INDENI is $300+$ men to about 25 women, it is 
difficult to come anywhere near equal representation especially since the HIV/AIDS Committee tries to include representatives from all the various departments at the plant. Originally there were supposed to be two women, but one was forced to drop out because of personal problems and she was replaced by a man from her section. All of the trainees have been members of INDENI's HIV/AIDS Committee for quite a while and all were trained as peer educators through the Morehouse/Copperbelt Health Education Project (CHEP). However, as one participant noted, "before this training I really had no idea what counseling was all about."

Culturally-specific content was interspersed throughout the workshop. In particular the training addressed topics such as: the main concepts of client-centered counseling within the extended family in Zambia; identification of cultural/traditional barriers to HIV/AIDS prevention and care; describing the stages of psychosexual development within the Zambian context; identifying cultural and spiritual issues related to death and dying (including issues of cleansing methods and inheritance); sexual practices within Zambia; cultural and social factors - myths and misconceptions; views and beliefs about the dangers of HIV transmission-myths and misconceptions; sensitive sexual issues within the local setting; and ethical issues in relation to the local culture. At the end of the training, it was emphasized that while the participants have gained new knowledge, they must also remain aware of the limitations in responding to specific situations. Particular stress was put on the importance of confidentiality and being able to advise clients on their legal and ethical rights.

The group was very enthusiastic about the training. They said they had never participated in a program that was so interesting and of such high quality throughout. They had nothing but praise for the facilitators. The most difficult part of the training was a session aimed at identifying sexual terminology in the vernacular languages. They found this exceedingly difficult. And while one participant said he now felt free enough to talk to anyone-male or female - about such subjects, others still felt a bit uncomfortable. Obviously the continuing difficulty in discussing intimate matters in the local language would again be addressed in the follow-up workshop.

The final exercise, however, probably had the greatest impact on the participants. It began with an announcement by the facilitator that all the participants would be expected to take an AIDS test (a very realistic possibility given that the training took place within a medical institution). They were then given some time to determine whether or not they would take the test and to define their reasons and reactions. This exercise was meant to test participants on how if feels to be a client. The participants emphasized that this exercise, along with others included in the training, really forced them to put themselves in their client's shoes and see things from their perspective.

Homework. All of the 10 facilitators were given six homework assignments to complete before returning for follow-up training in November. These activities were to be carried out at the workplace and/or in the community. Guidelines for carrying out the assignments were provided by the trainers, such as the guide to writing client case records and a verbatim interview record. The latter required that the facilitators record all the factors known about a client prior to the counseling session, how they prepared themselves for the session, their observations of the client as well as the person's verbal response. They were then asked to describe the psychological and social concerns of the 
client and outline what type of follow-up they planned to carry out with the individual. A series of questions at the end allowed the facilitator to critique her/his own performance. From among the counseling sessions carried out during this period, each participant was asked to select several to present during the follow-up workshop. In addition to the particulars of the case, they were to indicate why they selected this case for presentation and what particular response they were looking for from the other participants.

Mr. Joseph Nyirenda, the principal trainer, visited the trainees at the work site two or three times per week during this phase of the intervention. Trainees were also free to consult with him on an "as needed" basis. By the end of the exercise, each person had met with the trainer at least twice and was ready to hand in written reports of their homework assignments, as well as present their case studies to the group.

Follow-up Workshop. Nine of the ten trained facilitators attended the follow-up training workshop in November 1997. Again the event was held off-site at a facility in Ndola. The content of this workshop was based on the experience of the facilitators during the "homework" phase as indicated through the visits of the trainer the workplace and the content of their homework. A written assessment test was given at the conclusion of the workshop which all the participants passed. They were also assisted in developing work plans for the activities they would carry out once they returned to work.

Back to the Field. The facilitators then returned to work, incorporating culturally appropriate counseling into their peer education at both the workplace and in the community.

Training of Peer Educators from the Community. The main activity undertaken during the second phase of the intervention were training workshops for peer educators from INDENI's two community groups held in March and May 1998. This time four of the facilitators also served as trainers with the assistance of staff from the Counseling Unit and they were actively involved in developing the curriculum for this workshop. Twelve members of the women's groups (six from Ndeke, where most workers live, and six from Kansenshi, the management level compound), participated in the training.

\section{Outcomes}

The facilitators trained through this intervention and the INDENI management are very enthusiastic about their experience to date. The trainer from the Counseling Unit of the $\mathrm{MOH}$ further reported that this was one of the most cohesive groups he had worked with to date and that he was very impressed by their high level of interest and commitment.

Already the nurse in charge of the company's HIV/AIDS Committee has been approached by colleagues working for other industries in the Copperbelt area who are anxious to have an opportunity to learn from INDENI's experience. While the Ministry of Labour and Social Affairs workplace program is no longer active, some links between Zambia's major industries still exist and could, hopefully, be easily re-energized.

\section{Problems Encountered}

Few problems were encountered during the preparation or implementation of this intervention. Most, in fact, had to do with timing of the various intervention components which had to be adjusted on several occasions to complement the schedules at the work site or of the Counseling Unit. For example, shortly after completion of the first training, 
the INDENI plant "shut down" for a period so that necessary servicing and repair of equipment could take place. This activity, which lasted over a month, required that staff work around the clock in order to reduce the length of the shut down as much as possible. Therefore, it was impossible for the facilitators to embark on their homework assignments until the work schedule returned to normal.

Unfortunately, CHEP has yet to complete and produce new counseling materials in local languages. Therefore, the program has made use of materials produced by the Ndola HIV/AIDS task force where one of their counselors also serves.

\section{Next Steps}

After the peer educators have had a chance to practice their newly acquired skills, it is hoped that the required support can be obtained to carry out a comprehensive assessment of the effectiveness of the intervention. As a pre and post-test evaluation of knowledge and attitudes is not seen as being particularly useful — given that the internalization of information and concomitant modifications of behavior occur over time and are very hard, if not impossible to measure quantitatively--qualitative methods such as focus group discussions will be used as an initial measure of effectiveness along with a review of the counseling records kept by the facilitators and peer educators of their work in the field, and clinic records. Monitoring by the AIDS team in terms of numbers of clients coming for information, requesting services (HIV test, condoms), and other less overt signs of behavior and attitude change among a constituency they know very well will also help to assess the impact of the new approach at the work site and in the community. While a longer-term assessment is beyond the scope of this project, INDENI staff will be encouraged to seek additional means of monitoring the effectiveness of the new counseling format over a longer period of time.

As a first step, it is anticipated that a workshop will be held within the Copperbelt province to share INDENI's experience with representatives of other large industries located in the area as well as with representatives of the health community and local NGOs and to assess interest in introducing the culturally appropriate counseling approach in other settings. Representatives of INDENI's HIV/AIDS Committee who participated in the intervention, as well as their collaborators from the Counseling Unit of the University of Zambia, the Ministry of Health, and the Copperbelt Health Education Project (CHEP) would facilitate the workshop with the assistance of Council staff who have been involved in carrying out the Community-based AIDS in Africa project.

\section{Lessons Learned}

It is far too early to assess all of the lessons that will be learned through this intervention as the peer educators have just been trained and the facilitators have only had about six months of activity in the field. However, at this stage it is possible to say that:

1. The addition of important cultural components inherent in traditional approaches to seeking and providing health care, introduced within a participatory training framework, have greatly increased the confidence of the members of INDENI's HIV/AIDS Committee to address sensitive issues related to HIV/AIDS prevention and care with colleagues in the workplace and within the community. 
2. With appropriate technical support, facilitators trained in this way are, in turn, able to assume the role of trainer and participate in developing a curriculum to reach additional cadres of community workers.

3. The use of local resources for technical assistance has made possible ongoing support for the intervention beyond the training period to include the periods of fieldwork. It has also allowed for a two-way learning process to take place that holds the potential to improve the overall approach to HIV/AIDS counseling within Zambia.

4. Implementation of the intervention has generated considerable interest within other industries located in the Copperbelt region to introduce similar programs for their workers. 


\section{Summary of Activities Included in the First Workshop}

\section{Day One}

- Journal writing

- HIV/AIDS

- Myths, misconceptions, traditional beliefs

- HIV \& me (risk factors)

- Impact of HIV - family, community, and national

- Communication skills

\section{Day Two}

- Sensitive topics

- Sex/sexuality

- Safe sex

- Group dynamics

- Ideal counselor

- Introduction to counseling

- Interventions in counseling

- Purpose of counseling

\section{Day Three}

- Modules in counseling

- Techniques

- Interventions

- Problem solving/decision making

\section{Day Four}

- Counseling skills

- Feeling

- Empathy

- Sympathy

- Psycho-analysis

- Personality development

- Defense mechanism

\section{Day Five}

- Legal issues in counseling

- Testing issues

- Unresolved issues 


\title{
The Effectiveness of Providng Skills Traning to Older Orphans to Increase Their Ability to Support Themselves and Their Households
}

\author{
Kwasha Mukwenu (A Children in Distress Project) in Lusaka, Zambia
}

KWASHA MUKWENU is a Children in Distress (CINDI) project operating in the Matero district of Lusaka, the capital of Zambia, that is currently supporting a growing number of orphans in their community. While Kwasha Mukwenu makes every effort to keep as many of these children in school as possible, for many (especially those who are child heads of households) lack of cash for school fees, uniforms, and books, combined with responsibilities to their other siblings, makes this impossible. Frustration with their inability to help themselves or their families often forces such youngsters out into the streets to make do as best they can with all the risks that entails.

\section{Background}

Kwasha Mukwenu, which means "help your friend" in the local language, was founded in December 1991, initially by members of the women's group at St. Mary's Catholic

Church. In their own compounds, the women had already begun to experience deaths that were leaving children without parents to care for them. So when one of their members returned from a trip to Uganda where she had seen activities to support AIDS orphans in action, they decided to attempt a similar response in their community.

Each member of Kwasha Mukwenu-which has expanded beyond members of St. Mary's even though the group still operates from space provided by the church-looks after from three to five families of orphans in her immediate area. It is their responsibility to see that the orphans have food, medical care, clothes, shelter and, where possible, are able to remain in school. The group meets daily (Monday-Friday) at the church where members bake bread and scones which are sold to local schools. Some members also sew clothes as well as make floor mats while others produce tie and dye fabric. The profits from all of these enterprises are used to pay school fees and provide other necessities for the families in need. (For more information about the work of Kwasha Mukwenu, see the 1994 publication Case Studies from Five African Countries available from the Population Council or Glaxo Wellcome's Positive Action Programme.)

One of the major concerns identified by Kwasha Mukwenu during the development of the case studies in 1994 was the need to earn income to keep orphaned children in school and to find a way to help and support older orphans not able to continue their formal education. During the series of dissemination workshops carried out in 1995 as part of the Community-based AIDS in Africa project, this problem was repeatedly noted as one commonly faced by grassroots organizations such as Kwasha Mukwenu.

\section{Intervention}

In 1996, Kwasha Mukwenu was approached about the possibility of participating in an action-research intervention aimed at assisting the organization to expand on a small skillstraining/income-generating program they had begun that employed a few orphaned adolescents boys. Kwasha Mukwenu is now building on this first, small-scale effort by working with the Council's Associate for Reproductive Health based in Nairobi, Kenya, 
and a local consultant, Dr. Mubiana Macwan'gi, who was identified as having the necessary skills and connections to provide ongoing technical assistance. Working together, they have set out to test the hypothesis that:

\section{Provision of skills training to older orphans will significantly increase their ability to support themselves and their households while contributing to project sustainability.}

The Community Survey. The first activity undertaken was a household survey to identify the out-of-school adolescent orphans currently within Kwasha Mukwenu's project area and to find out the types of training that would be of interest to them. To carry out this survey, the consultant hired a team of ten orphaned young people who had completed secondary school and trained them in how to conduct interviews and fill out questionnaires. When the data was compiled, the consultant reconvened her research team for a dissemination meeting where they avidly discussed the findings outlined in Tables 1-4 (reproduced at the end of this section of the TDF file).

Selecting Appropriate Skills. At the same time the survey was being carried out, the consultant worked with Kwasha Mukwenu members to identify suitable training opportunities for these young people that would provide them with skills useful within the local economy. Equal attention was given to seeking opportunities to benefit both boys and girls. Based on the results of the survey and the resources available, it was determined that two training programs - one in tailoring and one in carpentry — would be established for a group of 10 youngsters each.

The Tailoring Workshop. Ten girls were enrolled in the tailoring workshop which began in the summer of 1997. (The workshop was not restricted to girls, but no boys showed an interest in participating.) The girls attend class Monday-Friday from 8:30 11:30 a.m. Two teachers provide instruction and receive a token payment for their work. They are in effect volunteering their time to Kwasha Mukwenu for this activity. Initially it was expected that the tailoring class would last one year. However, the girls learned so rapidly and worked so hard that they completed the course by spring 1998.

Ruth is 19. She finished standard eight but then her mother died last year. Now she lives with her uncle and his family. She has four brothers and sisters. Belinda is 18 and both her parents have died, her father in 1990 and her mother in 1995. There are six children in her family and they now live with her aunt and uncle. Pauline is also 19. She completed standard nine before her father died. There are seven children in her family. Dorothy, also 19, got as far as standard nine. Her father, who worked at a gas station, died in 1989 leaving her mother to support her and her six siblings. Now there are 11 children in their household, including Dorothy's infant daughter. Her mother works part-time on a foodfor-work program digging ditches. For this she gets some rice, beans, and cooking oil to help feed her family. 
The Carpentry Workshop. Start-up of the carpentry workshop (which will also include upholstery skills) initially was delayed to allow the tailoring project to get off the ground and because of some constraints on the consultant's time. An instructor living in Matero was identified who operates a carpentry and upholstery shop out of his home. When the project was first discussed with him, it was suggested that this training should also be open to girls. The instructor initially expressed complete amazement, but after some discussion, he said he would be willing to give it a try if any girls wanted to participate. (This seemed appropriate as it turned that he is also the father of six girls!) Unfortunately, no girls have yet asked to participate in the course.

Like the tailoring class, the carpentry classes take place at the Kwasha Mukwenu headquarters at St. Mary's church. A shed and open area have been made available for this purpose and tools purchased. Six adolescent boys began work in February. By late March, they had already managed to construct several armchairs which are now on display in the Kwasha Mukwenu headquarters. The carpentry training course will also include the opportunity for the youth to work as apprentices in their instructor's shop. Those who do well will be given an opportunity to be tested at the Industrial Training Center in Lusaka. Passing this exam results in receipt of a certificate which will improve their chances of getting a job in industry. As the carpentry instructor required full payment for his time, once the boys were given the basic skills, he was asked to come to the workshop every other day so that there will be sufficient funds for him to continue providing instruction and supervision through the life of the intervention.

\section{Outcomes}

Eight girls completed the tailoring workshop (one had to drop out to care for her young child and another did not want to continue after becoming pregnant) and are anxious to receive their certificates of completion. Now the girls are hopeful that they will be able to form a cooperative and work together to begin earning an income. In fact, the first Kw. 48,000 (US \$37) the girls earned from selling items produced during the workshop was used to get Kwasha Mukwenu's heavily used sewing machines a much needed servicing. Some of the workshop funds were also used to purchase fabric to make school uniforms. This is one of the principal items the girls hope to produce through their cooperative. They are also anxious to start a savings scheme where each one will invest Kw. 200 per month on a regular basis. Currently their money is being kept by the Kwasha Mukwenu treasurer in their own account.

During their training, the consultant arranged for visitors to come and talk to the girls about subjects aimed at helping them become independent and self-sufficient such as forming and operating cooperatives, operating a small business, how to present oneself to potential employers, etc. The consultant's interest in the group has been such that she has become a member of Kwasha Mukwenu.

\section{Problems Encountered}

Delays in getting the carpentry workshop up and running-partially caused by constraints on the consultant's time and the difficulty of locating a suitable instructor willing to work 
for the wages available - have resulted in a significant delay in the completion of this intervention. As of this writing, all of the final steps necessary to thoroughly evaluate the impact of the training programs cannot be carried out until completion of the carpentry classes, which will be later this year.

Another problem has been the difficulty in getting assistance for the girls group to start their cooperative. One expert who visited their class told them that it simply was not possible for adolescent girls to get credit and that was that! Yet these girls need to work-some in fact have children to support-and now they have the skills they need to earn a living. (This lack of programs willing to address the economic needs of adolescent girls is one reason why another Population Council initiative, known as Take Back Young Lives, is seeking to encourage provision of economic support to girls and young women.) Working with the women of Kwasha Mukwenu and Dr. Macwan' gi, the Council is attempting to help the girls set up their business. Most likely this will be done by involving some of the group's adult members in the cooperative, at least initially, in order to qualify them for credit and other types of assistance.

\section{Next Steps}

At the end of the second training workshop for boys, a set of profiles of each of the young people participating in the skills training will be undertaken. The consultant will again train her group of local "research assistants" to carry out this task. These young people will also be hired to carry out the follow-up household survey. This simple survey of household income and resources of participating youngsters made at the beginning of the intervention will be repeated in order to assess the impact of the intervention on these households. At the end the year, when the intervention is completed, Kwasha Mukwenu members will be assisted to complete a cost analysis comparing program costs with the benefits accruing to the participants, their families, and the project. Less immediately tangible benefits, such as prospects for future employment, avoidance of risky behavior, increased self-confidence, etc., will be documented anecdotally through in-depth interviews and focus-group discussions.

\section{Lessons Learned}

The following are some lessons that have been learned to date. A more complete set of lessons will not be available until completion of the follow up activities outlined in "Next Steps" above.

1. It is possible to identify skills of interest to young people and viable within the local economy, and to retain the services of individuals qualified to impart these skills, with a modest expenditure of outside financial support and technical assistance.

2. Young out-of-school youth are anxious to learn and to work and will apply themselves diligently if given a chance. Also, with the proper training and supervision, teenagers who have the equivalent of a high school education are quite capable of carrying out basic research within the local community. 
3. While it is too early to determine to what extent the training programs will generate a return to the Kwasha Mukwenu program, two tangible benefits have already accrued: the program has been able to give its sewing machines a muchneeded reconditioning and they now have several nice pieces of furniture in their headquarters.

4. While the follow-up interviews and survey will shed more light on the degree to which participation in the training courses has affected the lives of these out-of-school young people, some tangible benefits are already apparent. The exemplary attendance and hard work of the girls in the tailoring class has enabled them to complete their training ahead of schedule. In addition, these initially quiet, shy, and soft-spoken girls have now become a group of budding entrepreneurs anxious to express themselves and full of determination to succeed. 


\section{Findings from the Community Survey}

Table 1. Socio-Demographic Characteristcs of Orphans Eligible to Participate in the Intervention

\begin{tabular}{|c|c|c|}
\hline & No. & Percent \\
\hline \multicolumn{3}{|l|}{ Sex } \\
\hline Female & 103 & 41 \\
\hline Male & 146 & 59 \\
\hline Total & 249 & 100 \\
\hline \multicolumn{3}{|l|}{ Age in years } \\
\hline 14 & 12 & 5 \\
\hline $15-19$ & 139 & 56 \\
\hline $20-21$ & 98 & 39 \\
\hline Total & 249 & 100 \\
\hline \multicolumn{3}{|c|}{ Highest level of education completed (grade): } \\
\hline Less than 7 & 38 & 16 \\
\hline 7 & 102 & 42 \\
\hline 8 & 8 & 3 \\
\hline 9 & 57 & 24 \\
\hline $10-11$ & 6 & 2 \\
\hline 12 & 29 & 12 \\
\hline University & 3 & 1 \\
\hline Total & 243 & 100 \\
\hline \multicolumn{3}{|c|}{ Reasons for stopping school } \\
\hline Failed & 147 & 59 \\
\hline Poor health & 37 & 15 \\
\hline Lack of money & 30 & 12 \\
\hline Impregnated a girl & 26 & 10 \\
\hline Got pregnant & 9 & 4 \\
\hline Total & 249 & 100 \\
\hline
\end{tabular}


Table 2. Quality-of-Life Indicators

\begin{tabular}{lcc}
\hline Indicator & No. & Percent \\
\hline \multicolumn{3}{c}{ How do you spend most of your time? } \\
\hline Working & 111 & 39 \\
Playing & 86 & 30 \\
Help with housework & 68 & 24 \\
Other & 21 & 7 \\
Total & $\mathbf{2 8 6}$ & $\mathbf{1 0 0}$ \\
\hline \multicolumn{3}{c}{ Are you happy with what you are doing? } \\
\hline Yes & 19 & 8 \\
No & 230 & 92 \\
Total & $\mathbf{2 4 9}$ & $\mathbf{1 0 0}$ \\
\hline What do you feel you can do to make yourself \\
\multicolumn{4}{c}{ happy? } & \\
\hline Get employed & 71 & 31 \\
Complete school & 62 & 27 \\
Start your own business & 43 & 17 \\
Go to another technical & 22 & 10 \\
school & & \\
Get another chance & 17 & 7 \\
Go for training & 11 & 5 \\
Play football & 4 & 2 \\
Total & $\mathbf{2 3 0}$ & $\mathbf{1 0 0}$ \\
\hline
\end{tabular}

Table 3. Orphans Contributions to Running Their Household

\begin{tabular}{|c|c|c|}
\hline & No. & Percent \\
\hline \multicolumn{3}{|c|}{$\begin{array}{l}\text { Do you contribute to the running of this } \\
\text { household? }\end{array}$} \\
\hline Yes & 123 & 49 \\
\hline No & 126 & 51 \\
\hline Total & 249 & 100 \\
\hline \multicolumn{3}{|c|}{ Type of Contribution } \\
\hline Food & 44 & 36 \\
\hline Help with housework & 36 & 29 \\
\hline Money & 19 & 15 \\
\hline Care of children & 10 & 8 \\
\hline Other & 14 & 11 \\
\hline Total & 123 & 99 \\
\hline
\end{tabular}

Table 4. Skills Most Desired by Orphans 


\begin{tabular}{lccc}
\hline Skill & Female & Male & Total \\
\hline Tailoring/Design & 47 & 5 & 52 \\
Mechanics & 2 & 37 & 39 \\
Typing/Secretarial & 19 & 1 & 20 \\
Carpentry & 1 & 17 & 18 \\
Nursing & 11 & 2 & 13 \\
Other & 20 & 47 & 67 \\
Total & $\mathbf{1 0 0}$ & $\mathbf{1 0 9}$ & $\mathbf{2 0 9}$ \\
\hline
\end{tabular}

